\title{
Application of LC-DAD Metabolic Fingerprinting in Combination with PCA for Evaluation of Seasonality and Extraction Method on the Chemical Composition of Accessions from Lippia alba (Mill.) N. E. Brown and Biological Activities
}

\author{
Raphael A. de Jesus, ${ }^{a}$ Vilma M. J. Prado, ${ }^{a}$ Vanderson S. Pinto, ${ }^{b}$ Valdenizia R. Silva, ${ }^{c}$ \\ Luciano S. Santos, ${ }^{c}$ Paulo C. L. Nogueira, ${ }^{a}$ Sandro Navickiene, ${ }^{a}$ Edenir R. Pereira-Filho, ${ }^{\circledR d}$ \\ Arie F. Blank, ${ }^{b}$ Daniel P. Bezerra, ${ }^{\circ c}$ Milena B. P. Soares, ${ }^{c, e}$ Claudia Seidl, ${ }^{f}$ Carmen L. Cardoso ${ }^{f}$ \\ and Valéria R. S. Moraes ${ }^{\circledR} *, a$
}

${ }^{a}$ Departamento de Química, Universidade Federal de Sergipe, Av. Marechal Rondon, s/n, 49100-000 São Cristóvão-SE, Brazil

${ }^{b}$ Departamento de Engenharia Agronômica, Universidade Federal de Sergipe, Av. Marechal Rondon, s/n, 49100-000 São Cristóvão-SE, Brazil

'Instituto Gonçalo Moniz, Fundação Oswaldo Cruz, Rua Waldemar Falcão, 121, Candeal, 40296-710 Salvador-BA, Brazil

${ }^{d}$ Departamento de Química, Universidade Federal de São Carlos, Rodovia Washington Luiz, km 235, 13565-905 São Carlos-SP, Brazil

${ }^{e}$ Centro de Biotecnologia e Terapia Celular, Hospital São Rafael, Avenida São Rafael, 2152, São Marcos, 41253-190 Salvador-BA, Brazil

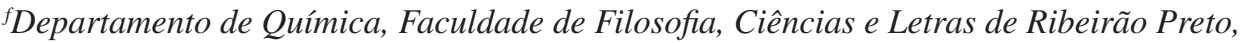
Universidade de São Paulo,14040-901 Ribeirão Preto-SP, Brazil

The methodology developed in this study through the acquisition of fingerprint chromatograms by liquid chromatography-diode array detector (LC-DAD), aided by principal component analysis, made it possible to assess, in a rational way, the chemical differences between six accessions of Lippia alba and to verify the influence of the method of extraction, the seasonality and the individuality of each accession on chemical composition of its extracts. Among all extracts analyzed against cancer cell lines, eight of them showed to be more promising against a human leukemia cell line (HL-60), displaying cell growth inhibition percentage ranging between 40.0 and $52.0 \%$. In the inhibitory activity assays against acetylcholinesterase enzyme, all extracts showed weak inhibitory effect, with highlight only for six of them, which displayed inhibition ranging between 27.0 and $32.0 \%$.

Keywords: Lippia alba (Mill.) N. E. Brown, fingerprint LC-DAD, PCA, polar extracts, biological activities

\section{Introduction}

Based on the extensive therapeutic use of several medicinal plants in folk medicine for the treatment of various diseases, more rational chemical and pharmacological studies regarding plants have became a challenge in the field of natural products chemistry. In this sense, the literature shows several studies that focus on the phytochemical profile combined with the evaluation of

*e-mail: valrsmoraes@uol.com.br their pharmacological potentials without the isolation of their active chemical constituents. ${ }^{1-3}$

Previous studies on essential oils and extracts obtained from several Lippia species (Verbenaceae family) have shown a great biological and economic potential due to the great chemical diversity of this genus, ${ }^{4}$ and describe important biological activities such as anti-inflammatory, ${ }^{5}$ anticholinesterase, ${ }^{6}$ photoprotective, ${ }^{1}$ cytotoxic, ${ }^{7}$ antioxidant, ${ }^{2,3}$ antiseptic, antimicrobial, antifungal and larvicidal. ${ }^{8,9}$

The genus Lippia comprises about 200 species of herbs, shrubs and small trees, which are distributed mainly 
throughout Central and South America and in tropical regions of Africa. ${ }^{10}$ Lippia alba (Mill.) N. E. Brown is a representative species of this genus, popularly known in Brazil as "erva-cidreira" or "falsa melissa", which is traditionally used in the treatment of various diseases such as gastrointestinal disorders, cutaneous diseases and inflammations. ${ }^{11}$ The secondary metabolites commonly found in $L$. alba extracts include iridoids, flavonoids and phenylpropanoids/phenylethenoids glycosylated derivatives, and the latter two display important antioxidant activities as mentioned in the literature. ${ }^{2,3}$

In addition, L. alba shows a high potential for pharmaceutical and agricultural industries because of its proven antifungal, insecticidal and repellent properties, related mainly to the major components present in its essential oil such as carvacrol, citral, limonene and carvone. ${ }^{12,13}$

The high demand for medicinal plants and their preparation requires attention to their quality, safety and efficacy, ${ }^{14}$ being, however, a major challenge due to their chemical complexity, possibility of adulterations and chemical variability. Consequently, there is a need for techniques and methodologies in order to carry out the monitoring of these parameters prior to the commercialization and/or use of these plant preparations, as well as to evaluate their possible harmful or beneficial effects on human health. ${ }^{15,16}$ In addition, studies evaluating the effects of seasonality, soil type and extraction method should be considered since they may alter the chemical composition of herbal preparations and may affect their therapeutic effects. ${ }^{2,17,18}$

Liquid chromatography (LC), mainly through the strategy of chromatographic fingerprints, has become an important alternative for the analysis, evaluation and identification of adulterations in preparations based on medicinal plants and also in industrialized medicines, ${ }^{17,19-21}$ which is one of the methodologies accepted by the World Health Organization (WHO) and the Food and Drug Administration (FDA) for the quality control of these preparations. ${ }^{22,23}$ Fingerprint chromatogram is characterized by demonstrating the chemical complexity of a plant sample through the best possible separation of a larger number of compounds, considering the limitations with respect to the chromatographic method and type of detector used. ${ }^{17,19}$ However, due to the large amount and complexity of the data generated by chromatographic techniques, such as LC-diode array detector (DAD), the use of chemometric methods, like principal component analysis (PCA), is necessary for the treatment and obtaining of relevant information from original data, in order to make the chemical analyses faster and more objective..$^{20,24,25}$
Therefore, the objective of this work was to develop a chromatographic fingerprint, by LC-DAD, for the chemical differentiation of six accessions of L. alba (Mill.) N. E. Brown, aided by PCA, and to evaluate the influence of the extraction method (infusion and hydroalcoholic maceration) and the seasonality (summer and winter) on the chemical composition of its extracts. In order to evaluate the seasonality, the seasons considered for the collection were only summer and winter due to the fact that in the northeast of Brazil these two seasons are the most different in relation to rainfall rates (water precipitation), which may cause more stress upon this species. ${ }^{18}$

In addition, the cytotoxic and anticholinesterase activities of all extracts were evaluated in order to identify which accession is the most promising from the biological point of view, taking into account also the collection period and the extraction method. These results will support the selection of individuals of this species destined to the cultivation and maintenance of their genetic diversity through techniques developed by the Laboratory of Tissue Culture and Plant Breeding of the Departamento de Engenharia Agronômica, Universidade Federal de Sergipe (UFS), São Cristóvão, SE, Brazil, aiming to obtain extracts with better pharmacological potential.

\section{Experimental}

\section{Solvents and materials}

LC grade acetonitrile (Tedia, Fairfield, OH, USA) and methanol (J. T. Baker, Philipsburg, PA, USA) were used in the LC analysis. Ethanol was purchased from PanReac (Barcelona, Spain). Analytical grade formic acid (88\%) was purchased from J. T. Baker. Deionized water was obtained using Milli-Q system (Millipore, São Paulo, SP, Brazil). Acetylcholinesterase (AchE) from electric eel (AChEeel) type VI-S, acetylcholine iodine (ACh), ammonium acetate, galanthamine hydrobromide, dimethylsulfoxide (DMSO; 99.9\%) and resazurin (alamarBlue) were obtained from Sigma-Aldrich (St. Louis, MO, USA). Doxorubicin (purity $>95 \%$ ) was purchased from Laboratorios IMA (Buenos Aires, Argentina). Human cancer cell lines HL-60 (promyelocytic leukemia) and HepG2 (hepatocellular carcinoma) and human non-cancer cell line MRC-5 (lung fibroblast) were obtained from the American Type Culture Collection (ATCC; Manassas, VA, USA). All other reagents were analytical grade or higher.

\section{General experimental procedures}

The LC analyses were carried out using a Shimadzu 
Prominence LC (Kyoto, Japan), equipped with a DGU-20A3 vacuum degasser, SIL-20AHT autosampler, two LC-20AT high pressure pumps, a CTO-20A column oven and an SPD-M20A DAD system coupled with a CBM-20A interface. Data collection was performed using Shimadzu LC Solution software. For sample preparation and LC analyses, deionized water and solvents such as acetonitrile, methanol and $88 \%$ formic acid (v/v) were used. The elution solvents were degassed by ultrasonic bath before use.

\section{Plant material}

Leaf samples of six L. alba accessions called LA01, LA02, LA24, LA32, LA39 and LA54 (SISGEN register number A8CCB3B) were collected on March $14^{\text {th }}$ (summer) and September 20 ${ }^{\text {th }}$ (winter) 2016 from Research Station "Campus Rural da UFS", located in the municipality of São Cristóvão, Sergipe State, Brazil. All the voucher specimens (14784, 14785, 13477, 13480, 13497 and 13478 , respectively) were deposited in the UFS Herbarium, Departamento de Biologia, UFS. The leaves were dried in a forced air circulation oven at $40{ }^{\circ} \mathrm{C}$ for five days.

\section{Extracts preparation}

The aqueous extracts were prepared by infusion method, where $200 \mathrm{~mL}$ of ultrapure water at $92{ }^{\circ} \mathrm{C}$ (heated in a microwave oven) were added to $2.0 \mathrm{~g}$ of leaves and left for $10 \mathrm{~min}$ at room temperature, then filtered through analytical paper, frozen in an ultrafreezer at $-79^{\circ} \mathrm{C}$ (Liotop UFR30, Liobras, São Carlos, SP, Brazil), and lyophilized (Liotop L101, Liobras) at $-54{ }^{\circ} \mathrm{C}$ and pressure of $79 \mu \mathrm{mHg}$. The hydroalcoholic extracts were prepared using the maceration method, where $2.0 \mathrm{~g}$ of leaves were added to $100 \mathrm{~mL}$ of a solution with equal volume of ultrapure water:ethanol mixture $(1: 1 \mathrm{v} / \mathrm{v})$, then left for $24 \mathrm{~h}$. Each extract was filtered through analytical paper then evaporated under reduced pressure to remove the organic solvent. The remaining aqueous solution was frozen in an ultrafreezer and lyophilized under the same conditions as the aqueous extracts.

\section{Sample preparation and chromatographic conditions of analysis}

The aqueous samples were prepared by dissolving $5.0 \mathrm{mg}$ of the extracts in $1 \mathrm{~mL}$ of ultrapure water, while the hydroalcoholic samples were prepared by dissolving $5.0 \mathrm{mg}$ of the extracts in $1 \mathrm{~mL}$ of a solution containing acetonitrile and ultrapure water $(4: 6 \mathrm{v} / \mathrm{v})$. All the solutions were vortexed for a few seconds and then centrifuged (Eppendorf minispin, BioResearch, São Paulo, SP, Brazil) at $13,300 \mathrm{rpm}(11,866 \mathrm{~g}$ force $)$ for $5 \mathrm{~min}$ prior to the LC analyses. This procedure was made in quadruplicate for each sample. Chromatographic analyses were performed on the analytical Kinetex $\mathrm{C}_{18}$ column $(250 \times 4.6 \mathrm{~mm}$ i.d., $5 \mu \mathrm{m}$; Phenomenex, Torrance, CA, USA) with the following conditions: mobile phase consisting of $0.5 \%(\mathrm{v} / \mathrm{v})$ aqueous formic acid (A) and acetonitrile (B). The gradient elution was $5-15 \%$ B for $20 \mathrm{~min}, 15-19 \%$ B for $40 \mathrm{~min}$, $19-100 \%$ B for $5 \mathrm{~min}, 100 \%$ isocratic B for $10 \mathrm{~min}$. The system was returned to the initial conditions in $5 \mathrm{~min}$, and the column was conditioned before the next injection for $55 \mathrm{~min}$. The flow rate of the mobile phase was $0.8 \mathrm{~mL} \mathrm{~min}^{-1}$, injection volume of the sample was $25.0 \mu \mathrm{L}$, and column oven temperature was $45^{\circ} \mathrm{C}$. Monitoring was performed at $240 \mathrm{~nm}$.

\section{Chemometric analysis}

Multivariate data analyses were carried out using Pirouette v.4.0 software. ${ }^{26}$ Pretreatment (peak alignment by the correlation optimized warping technique) and preprocessing (mean centered) of the data matrices were applied,following the methodology described in the literature. ${ }^{27}$

\section{In vitro cytotoxicity}

The cell lines (HL-60, HepG2 and MRC-5) were cultured in complete medium with appropriate supplements as recommended by ATCC, and were tested for mycoplasma using mycoplasma stain kit (Sigma-Aldrich, St. Louis, USA), and all cells were free from contamination. Cell viability was quantified using the alamarBlue assay and performed as previously described in the literature. ${ }^{28}$

\section{On-flow immobilized acetylcholinesterase inhibition studies}

The AChEeel $\left(2 \mathrm{U} \mathrm{mL}^{-1}\right)$ was immobilized into a fused silica capillary as previously described elsewhere..$^{29,30} \mathrm{The}$ resulting AChEeel immobilized enzyme reactor (AChEeelICER) was placed in the column compartment of the NEXERA LC system (Shimadzu, Kyoto, Japan) coupled to an AmaZon Speed ion trap (IT) mass spectrometer (MS) (Bruker Daltonics, Bremen, Germany) equipped with an electrospray ionization (ESI) source. The LC-MS system was controlled by and data was acquired using Bruker Data Analysis software (version 4.3). Detailed instrument description and MS parameters are described in Vilela et $_{\text {al. }}{ }^{30}$ 
Stock solutions $\left(5 \mathrm{mg} \mathrm{mL}^{-1}\right)$ of each sample were prepared in suitable solvents according to their method of extraction. Samples characterized as infusion were solubilized in ultrapure water. Those characterized as hydroalcoholic solution were solubilized in a hydroalcoholic solution (1:1). The solubilization of each stock solution was aided by ultrasonic bath maceration for $5 \mathrm{~min}$ at room temperature. Subsequently, each solution was centrifuged (Eppendorf minispin) for $5 \mathrm{~min}$ at $10,000 \mathrm{rpm}(6,708 \mathrm{~g}$ force). Working solutions $\left(2 \mathrm{mg} \mathrm{mL}^{-1}\right)$ were further prepared in ultrapure water.

Activity and inhibition studies were performed according to Vanzolini et al. ${ }^{31}$ with a few modifications. Briefly, reaction mixtures $(10 \mu \mathrm{L})$ containing $200 \mu \mathrm{gL}^{-1}$ of each sample and $70 \mu \mathrm{M}$ ACh (final volume completed with $15 \mathrm{mmol} \mathrm{L}^{-1} \mathrm{pH} 8.0$ ammonium acetate) were injected into the LC-MS system and the percentage of inhibition was obtained by the direct quantification of the peak area of the enzymatic reaction product ion choline $\left(\mathrm{Ch} ;[\mathrm{M}+\mathrm{H}]^{+}\right.$ $\mathrm{m} / \mathrm{z}$ 104.17) after the hydrolysis of ACh in accordance with equation 1 :

$\%$ of inhibition $=\left[1-\frac{\mathrm{P}_{\mathrm{i}}}{\mathrm{P}_{0}}\right] \times 100$

where $\mathrm{P}$ is the achieved peak area of $\mathrm{Ch}$ produced in the presence $\left(\mathrm{P}_{\mathrm{i}}\right)$ and absence of ligand $\left(\mathrm{P}_{0}\right)$.

Each reaction mixture was prepared in duplicate, analyzed twice and the results are the mean of two independent measurements. Galanthamine solution was used as positive control $(100 \mu \mathrm{M})$. Induced substrate hydrolysis was verified injecting the reaction mixture into the LC-MS system on an empty fused silica capillary. When any $\mathrm{Ch}$ of $[\mathrm{M}+\mathrm{H}]^{+} \mathrm{m} / z, 104$ is detected, the corresponding area must be subtracted from the experimental enzymatic hydrolysis values before calculating the sample true inhibition percentage.

\section{Results and Discussion}

\section{Optimizations of chromatographic conditions}

Considering that medicinal herbs preparations are of high chemical complexity, obtaining a representative fingerprint chromatogram with greater number of detectable bands, better resolution, shorter analysis time and good baseline stability, ${ }^{19,32}$ depends strongly on the degree of separation between its constituents. Consequently, the chromatographic analysis of such preparations is not trivial, therefore, it is necessary the development of a separation method specific for each type of sample..$^{21,33}$
Thus, in order to obtain the fingerprint chromatograms of $L$. alba extracts, previous optimizations were carried out by evaluating the following factors: the nature of the stationary phase, such as Kinetex C18 $(250 \times 4.6 \mathrm{~mm}$, $5 \mu \mathrm{m})$ and Kinetex phenyl-hexyl $(150 \times 4.6 \mathrm{~mm}$, $5 \mu \mathrm{m}$; Phenomenex); organic modifier (methanol and acetonitrile); the effect of whether using or not an acidic aqueous solution (with $0.5 \% \mathrm{v} / \mathrm{v}$ formic acid); column temperature $\left(24,30,35,40,45\right.$ and $\left.50^{\circ} \mathrm{C}\right)$; mobile phase flow $\left(0.8,1.0\right.$ and $\left.1.2 \mathrm{~mL} \mathrm{~min}^{-1}\right)$; gradient shape and wavelength for the detection of compounds (between 200 and $400 \mathrm{~nm}$, based on the secondary metabolites commonly found in this species). ${ }^{34-36}$

The best separation method was obtained by using these analyses conditions: Kinetex C18 column; mobile phase consisting of $0.5 \%$ aqueous formic acid (v/v; A) and acetonitrile (B); solvent flow rate: $0.8 \mathrm{~mL} \mathrm{~min}^{-1}$, temperature of $45^{\circ} \mathrm{C}$ and wavelength of $240 \mathrm{~nm}$, which was selected from the 3D graph obtained by the use of diode array detector, using gradient elution.

The chromatograms obtained for each sample in these conditions, considering the average of the quadruplicate analyses, are shown in Figure 1, whereby the chemical differences and similarities between the samples from the accessions can be observed considering each extraction method (infusion (I) and hydroalcoholic (H) maceration) and collection season (summer (S) and winter (W)), however, they are difficult to interpret visually.

Based on the results presented in Figure 1, the method developed is suitable when it comes to the obtaining fingerprint chromatograms with good separation between the bands, providing a good representation of the chemical profile of each extract.

\section{Analysis by PCA}

PCA is a very useful chemometric tool for the analysis of complex plant extracts because it reduces the dimensionality of the data without losing relevant information, promoting at the same time the analysis of the results in a more efficient and objective way. In addition, it is possible to verify which variables are mainly responsible for the clustering of samples. Thus, in order to evaluate the effect of the seasonality and the extraction method on the chemical composition of the extracts obtained from L. alba, PCA was performed based on their chromatographic fingerprints. ${ }^{37-39}$ The chromatographic methodology was applied to each sample in quadruplicate, in which its repeatability was evaluated. Afterwards, the average data of the quadruplicate analyses was submitted to PCA analysis. 

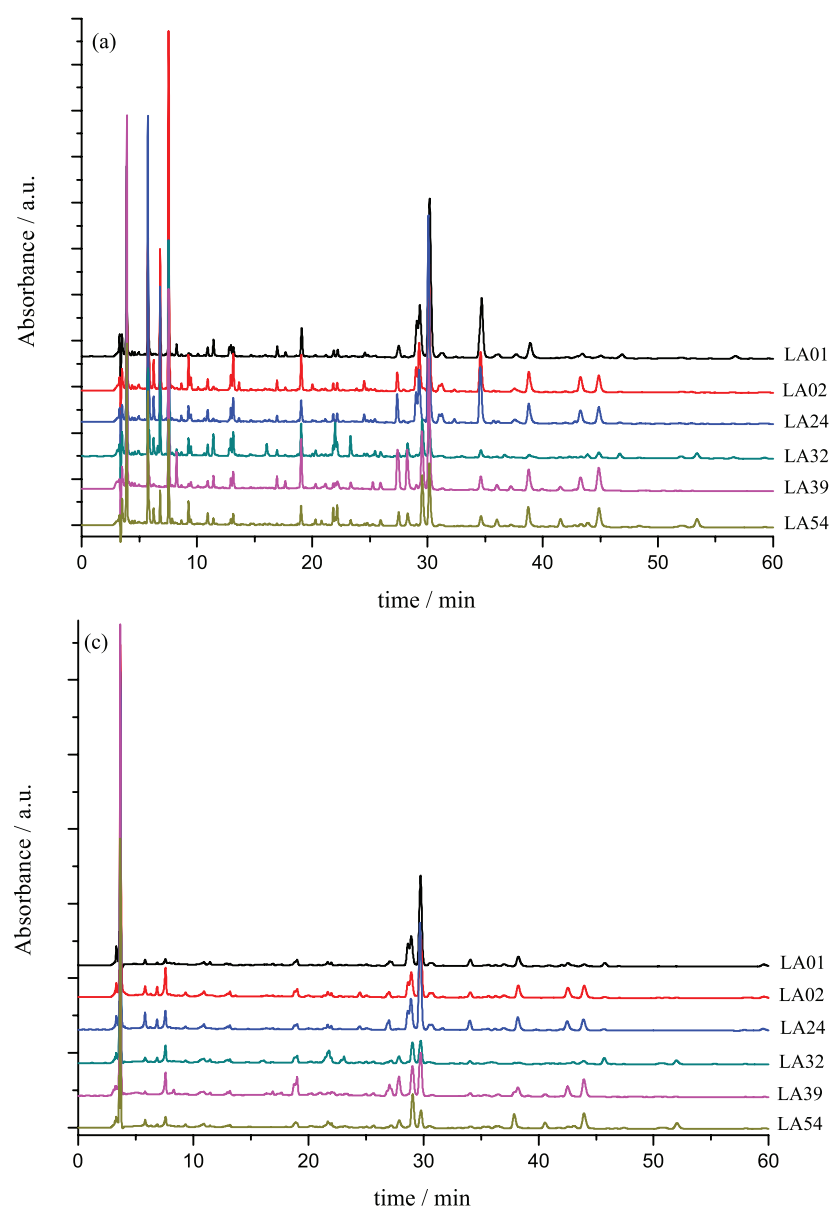
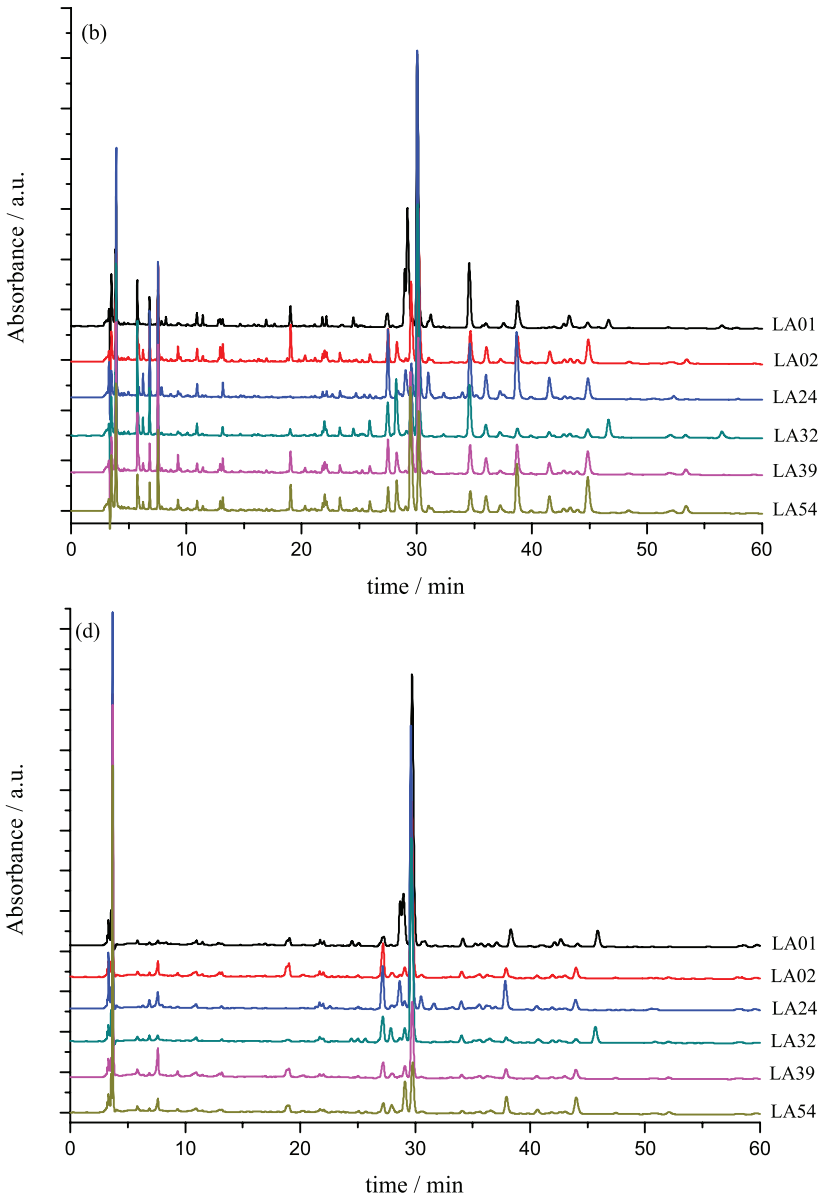

Figure 1. Fingerprint chromatograms of $L$. alba extracts from six different accessions, prepared by different methods and collected in different seasons: (a) infusion summer; (b) infusion winter; (c) hydroalcoholic summer; and (d) hydroalcoholic winter, using the optimized conditions and detection at 240 nm.

After pretreatment and preprocessing, the chromatographic data were organized into a matrix containing 24 lines (samples) and 563 columns (variables: retention time, $60 \mathrm{~min}$ ) and then submitted to PCA, providing dimensionality reduction for two new coordinates, generating the score graph PC1 vs. PC2 (Figure 2). ${ }^{19,40,41}$ The first two PCs together explain $71.8 \%$ of the total data variance $(\mathrm{PC} 1=47.0 \%$ and $\mathrm{PC} 2=24.8 \%)$ and, therefore, were selected to visualize the correlations among the samples (Figure 2).

In the PC1 vs. PC2 scores graph (Figure 2) it is possible to see the separation and the clustering tendency among the samples, originating several groups named from G1 to G5. The developed methodology showed good repeatability, since the quadruplicates of each extract showed great similarities among them.

The PCA graph shows that the accessions LA02, LA24 and LA32 had a significant seasonality effect considering the hydroalcoholic extracts, since their respective winter (LA02HW, LA24HW, LA32HW) and summer (LA02HS, LA24HS, LA32HS) samples are located in distinct groups, winter in G2 and summer in G1. On the other hand,

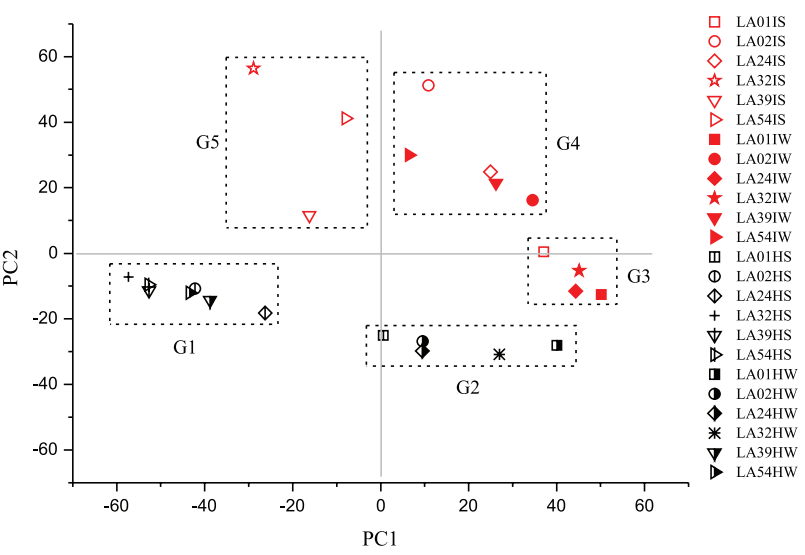

Figure 2. PC1 (47.0\%) vs. PC2 (24.8\%) biplot of the L. alba samples.

accessions LA01, LA39 and LA54 did not suffer significant influence from seasonality, due to the respective summer and winter samples clustering: LA01HW with LA01HS in G2; LA39HW with LA39HS and LA54HS with LA54HW in G1.

Considering the infusion method, the seasonality affected the chemical composition of the accessions LA24, LA32, LA39 and LA54, because their respective 
summer and winter samples are not in the same group: LA32IS, LA39IS and LA54IS in G5; LA24IS, LA39IW and LA54IW in G4; and LA24IW, LA32IW in G3. The accessions LA01 and LA02 were the exceptions, whose summer samples are grouping with the winter ones: LA01IS and LA01IW in G3 and LA02IS and LA02IW in G4 and, therefore, do not suffer significant effect from seasonality.

Evaluating the differences among the accessions, specifically through the samples prepared by IS, it was not possible to differentiate the LA02 from the LA24, as well as the LA32, LA39 and LA54 among themselves, because the former two are clustered in G4 and the latter two are in G5. On the other hand, the accession LA01 showed no correlation with any of the previous ones, since its sample is located in G3. When evaluating the samples prepared by IW, it was possible to verify the great chemical similarity among the accessions LA01, LA24 and LA32, since their samples are clustered in G3. Similarly, the accessions LA02, LA39 and LA54 do not differentiate among themselves (samples clustered in G4), but they are chemically different from the others. Analyzing the accessions, considering the samples prepared by HS, most of them could not be differentiated, since their samples are clustered in G1, except the LA01 (in G2). Considering the HW samples, four accessions presented similarities among themselves, since they were clustered in G2, differing, however, from accessions LA39 and LA54 (in G1).

The results discussed above suggest that accessions LA39 and LA54 are genetically similar, due to the clustering of their extracts from the same method and collected in the same season: LA39IW and LA54IW in G4; LA39IS and LA54IS in G5; LA39HW, LA54HW, LA39HS and LA54HS in G1.

Similar behavior was observed in the study reported by Blank et al., ${ }^{12}$ with 48 accessions of L. alba. The

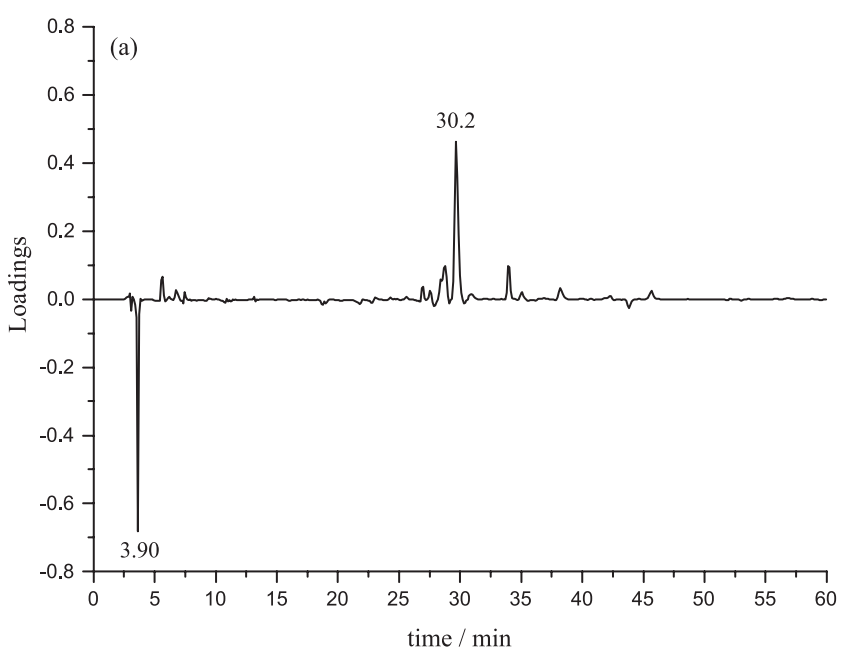

Figure 3. Loadings plot of L. alba samples. (a) PC1 and (b) PC2. authors found out that the accessions LA39 and LA54 are very similar through the chemical characterization of the essential oils from this species.

In addition, by using PCA, it was possible to identify the great influence of the extraction method on the chemical composition of the extracts obtained from this species, because there is a trend towards the formation of two distinct groups in the scores plot: one containing the infusion samples (G3, G4 and G5) and the other formed by hydroalcoholic samples (G1 and G2) (Figure 2).

In order to evaluate the correlations among the samples observed in the PCA graph, the loadings plot (Figure 3) is also analyzed, from which it is possible to explain the clusterings among the samples, observing which variables are more important to characterize them. ${ }^{17,40}$ In this way, the loadings plot shows which variables (chromatographic bands) have great influence (weight) in the projection of the samples in each PC that presents variables with positive and negative values. Thus, as samples LA01HW, LA02HW, LA24HW, LA32HW (G2); LA01IS, LA01IW, LA24IW, LA32IW (G3); and LA02IS, LA02IW, LA24IS, LA39IW, LA54IW (G4) presented positive values for PC1 (Figure 2), they are characterized by chromatographic band with retention time of $30.2 \mathrm{~min}$ that presents positive values, for this PC (Figure 3a), in the loadings plot. The cluster formed by the samples LA02HS, LA24HS, LA32HS, LA39HS, LA54HS, LA39HW, LA54HW (G1) and LA32IS, LA39IS, LA54IS (G5) are characterized by the chromatographic band with retention time of $3.90 \mathrm{~min}$.

The loadings of PC2 (Figure 3b) also present variables with positive and negative values. So, chromatographic bands with retention times of 5.74, 6.78, 7.53 and $29.5 \mathrm{~min}$, which present positive values for PC2, are responsible for the correlation among samples LA02IS, LA02IW, LA24IS, LA39IW and LA54IW (G4) and LA32IS,

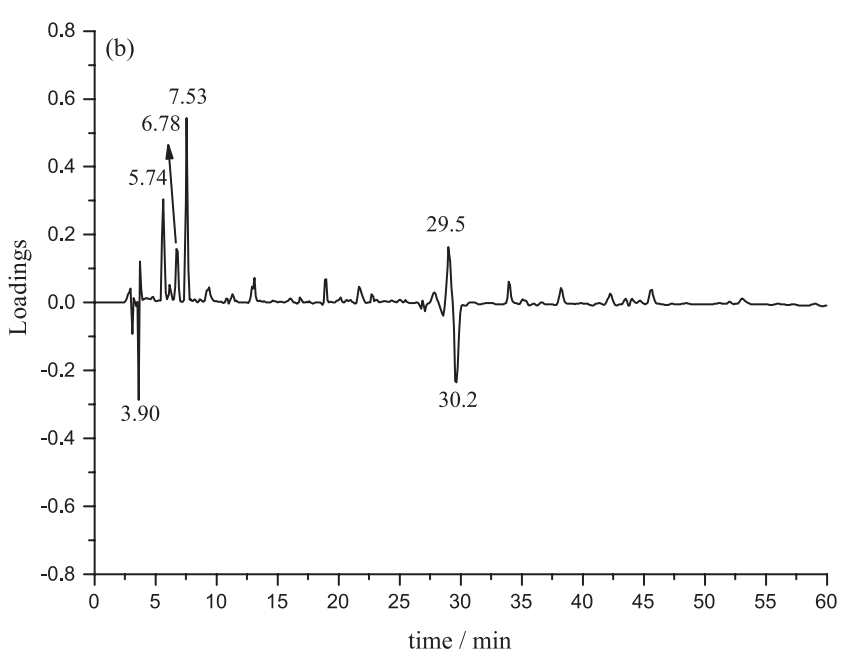


LA39IS, LA54IS (G5). In addition, it can be assumed that these latter compounds are characteristic of most of the infusion samples (summer and winter), since the samples LA02HS, LA24HS, LA32HS, LA39HS, LA54HS, LA39HW, LA54HW (G1); LA01HS, LA01HW, LA02HW, LA24HW, LA32HW (G2); and LA01IW, LA24IW, LA32IW (G3) present negative values of scores for PC2, being characterized by bands with retention times of 3.90 and $30.2 \mathrm{~min}$.

Besides, the chromatographic band at $3.90 \mathrm{~min}$ is the main responsible for the grouping of the samples LA39HW and LA54HW with the majority of hydroalcoholic summer samples (G1) and also for the differentiation of the latter from the LA01HS (G2), which presents score values close to zero in PC1. The chromatographic band at $30.2 \mathrm{~min}$ is responsible for the projection of samples LA01HW, LA02HW, LA24HW, LA32HW, LA01IW, LA24IW and LA32IW in positive score values in PC1 and negative in $\mathrm{PC} 2$, and for the discrimination of most $\mathrm{HW}$ samples and others (LA39HW and LA54HW).

\section{Cytotoxicity and enzymatic inhibition of acetylcholinesterase assays}

The in vitro assays of enzymatic inhibition against acetylcholinesterase enzyme and cytotoxicity against HL-60 and HepG2 cancer cells performed in this work are part of an initial screening to verify the anticholinesterase and anticancer potential of L. alba extracts. Table 1 presents the cell growth inhibition percentage of all extracts tested at a concentration of $50 \mu \mathrm{g} \mathrm{mL}^{-1}$, using doxorubicin as a positive control.

No extract was considered active against the tested cell lines, since they presented a percentage of cell growth inhibition lower than $75 \%$ (Table 1). ${ }^{28}$ However, the activities presented by extracts LA01IW, LA01HS, LA02IW, LA02HW, LA24HW, LA24HS, LA39HW and LA54HW against HL-60 cells can be highlighted, with inhibition percentages varying from approximately 40.0 to $52.0 \%$. These more promising results may be related to the individuality of each accession associated with the extraction method and the seasonality, resulting in extracts with particular chemical composition to display such activities. Thus, it is assumed that glycosylated phenylpropanoids and flavonoids, classes of secondary metabolites characteristic of this species, are responsible for these activities, since they are recognized for their antioxidant and antitumor activities. ${ }^{2,3,42-45}$

The anticholinesterase assays basically consist of monitoring the product resulting from the enzymatic hydrolysis of ACh, choline $(\mathrm{m} / \mathrm{z}, 104)$, which is quantified by MS. ${ }^{30,31,46}$ Table 2 shows the results obtained from this screening for each extract from $L$. alba at the concentration of $200 \mu \mathrm{g} \mathrm{mL} \mathrm{m}^{-1}$.

The results shown in Table 2 indicate that the extracts studied had a low inhibitory effect when compared to

Table 1. Cell growth inhibition percentage against cancer and non-cancer cell lines

\begin{tabular}{|c|c|c|c|c|c|c|c|}
\hline \multirow{2}{*}{ Sample } & \multicolumn{3}{|c|}{ Cell $^{\mathrm{a}}$ growth inhibition ${ }^{\mathrm{b}} / \%$} & \multirow{2}{*}{ Sample } & \multicolumn{3}{|c|}{ Cell $^{\mathrm{a}}$ growth inhibition $\mathrm{b} \%$} \\
\hline & HepG2 & HL-60 & MRC-5 & & HepG2 & HL-60 & MRC-5 \\
\hline LA01IS & $5.1 \pm 1.6$ & $7.1 \pm 1.8$ & $6.7 \pm 8.0$ & LA01HS & $4.1 \pm 0.2$ & $51.4 \pm 4.7$ & $13.8 \pm 1.4$ \\
\hline LA02IS & $1.1 \pm 0.7$ & $31.6 \pm 5.8$ & $3.8 \pm 0.3$ & LA02HS & $1.2 \pm 1.5$ & $12.4 \pm 4.2$ & $16.6 \pm 1.9$ \\
\hline LA24IS & $13.3 \pm 1.2$ & $36.6 \pm 5.2$ & $5.2 \pm 1.8$ & LA24HS & $10.0 \pm 6.5$ & $52.5 \pm 5.5$ & $33.4 \pm 7.2$ \\
\hline LA32IS & $7.5 \pm 3.3$ & $23.0 \pm 7.6$ & $7.7 \pm 1.7$ & LA32HS & $2.0 \pm 5.1$ & $39.6 \pm 9.5$ & $8.2 \pm 1.9$ \\
\hline LA39IS & $3.1 \pm 1.1$ & $15.9 \pm 1.3$ & $28.1 \pm 6.5$ & LA39HS & $7.1 \pm 3.1$ & $30.1 \pm 1.9$ & $14.4 \pm 1.7$ \\
\hline LA54IS & $5.3 \pm 1.7$ & $24.7 \pm 8.1$ & $32.2 \pm 7.5$ & LA54HS & $3.3 \pm 1.1$ & $26.7 \pm 3.6$ & $14.5 \pm 1.7$ \\
\hline LA01IW & $4.3 \pm 0.2$ & $47.8 \pm 5.0$ & $0.3 \pm 0.1$ & LA01HW & $7.5 \pm 2.3$ & $7.4 \pm 2.6$ & $21.4 \pm 1.8$ \\
\hline LA02IW & $13.2 \pm 4.8$ & $49.3 \pm 2.0$ & $17.6 \pm 3.2$ & LA02HW & $7.0 \pm 0.9$ & $41.7 \pm 6.5$ & $30.8 \pm 6.5$ \\
\hline LA24IW & $21.0 \pm 7.7$ & $27.3 \pm 7.1$ & $27.4 \pm 2.1$ & LA24HW & $7.1 \pm 6.9$ & $40.1 \pm 8.4$ & $13.3 \pm 1.7$ \\
\hline LA32IW & $18.9 \pm 5.6$ & $27.4 \pm 9.5$ & $9.7 \pm 1.1$ & LA32HW & $1.4 \pm 3.5$ & $24.8 \pm 7.1$ & $2.1 \pm 17.6$ \\
\hline LA39IW & $5.4 \pm 2.6$ & $21.0 \pm 4.6$ & $9.2 \pm 2.9$ & LA39HW & $17.1 \pm 6.8$ & $49.6 \pm 3.5$ & $14.5 \pm 1.7$ \\
\hline LA54IW & $14.6 \pm 4.1$ & $30.3 \pm 4.7$ & $17.8 \pm 3.3$ & LA54HW & $17.8 \pm 7.5$ & $40.8 \pm 7.6$ & $15.9 \pm 7.7$ \\
\hline Doxorubicin $^{c}$ & $87.9 \pm 5.6$ & $91.3 \pm 4.0$ & $95.1 \pm 5.0$ & & & & \\
\hline
\end{tabular}

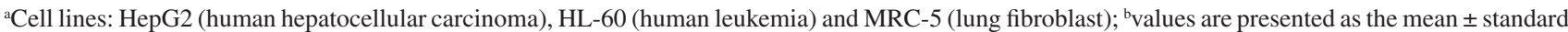
error of the mean from three replicates measured by the alamarBlue assay after $72 \mathrm{~h}$ of incubation. All extracts were tested at a concentration of

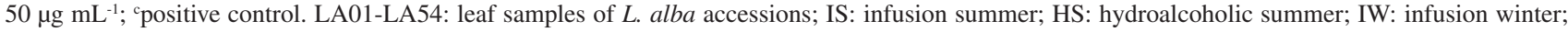
HW: hydroalcoholic winter. 
Table 2. Inhibition percentage of the activity of the AChE-ICER

\begin{tabular}{lccc}
\hline Sample & $\begin{array}{c}\text { AChE-ICER } \\
\text { inhibition } \\
\text { activity / } \%\end{array}$ & Sample & $\begin{array}{c}\text { AChE-ICER } \\
\text { inhibition } \\
\text { activity / \% }\end{array}$ \\
\hline LA01IS & $6.70 \pm 0.8$ & LA01HS & $32.7 \pm 3.3$ \\
LA02IS & $14.6 \pm 2.4$ & LA02HS & $27.4 \pm 0.7$ \\
LA24IS & $18.0 \pm 1.3$ & LA24HS & $30.3 \pm 4.1$ \\
LA32IS & $13.4 \pm 0.9$ & LA32HS & $6.70 \pm 0.5$ \\
LA39IS & $17.1 \pm 1.7$ & LA39HS & $18.5 \pm 4.0$ \\
LA54IS & $16.1 \pm 1.1$ & LA54HS & $24.5 \pm 0.7$ \\
LA01IW & $10.3 \pm 4.7$ & LA01HW & $28.4 \pm 0.2$ \\
LA02IW & $7.60 \pm 3.8$ & LA02HW & $27.2 \pm 0.3$ \\
LA24IW & $15.0 \pm 1.1$ & LA24HW & $24.4 \pm 3.2$ \\
LA32IW & $11.5 \pm 1.1$ & LA32HW & $22.2 \pm 0.8$ \\
LA39IW & $23.3 \pm 1.6$ & LA39HW & $23.2 \pm 1.6$ \\
LA54IW & $14.4 \pm 0.1$ & LA54HW & $29.3 \pm 4.5$ \\
Galanthamine ${ }^{a}$ & $87.4 \pm 2.2$ & & \\
\hline
\end{tabular}

a Positive control of acetylcholinesterase (AchE; $100 \mu \mathrm{M})$. AChE-ICER: AChE immobilized enzyme reactor; LA01-LA54: leaf samples of L. alba accessions; IS: infusion summer; HS: hydroalcoholic summer; IW: infusion winter; HW: hydroalcoholic winter.

standard reversible inhibitor (galanthamine), with emphasis only on LA01HS, LA02HS, LA24HS, LA01HW, LA02HW and LA54HW that presented percentage above $25 \%$ of enzyme inhibition.

The low activity displayed by the extracts against AChE may be related to antagonistic effects among the constituents present in these extracts, even though this species contains several flavonoids and glycosylated phenylpropanoids that may inhibit the anticholinesterase activity, as previously reported in the literature for derivatives of these classes of compounds. ${ }^{47-49}$

Previous studies that evaluated the anticholinesterase activity of $L$. alba showed divergent results that are supposedly related to the type of extract and analysis method used. Trevisan et al. ${ }^{6}$ reported low enzymatic inhibition activity against AChE, in microplate assays, of the ethanol extract from L. alba leaves, whereas Morais et al. ${ }^{50}$ observed significant inhibition activity of the hydroalcoholic extract (ethanol:water 95:5) of aerial parts through enzymatic inhibition assays in thin layer chromatography (TLC), similar to carbaxol.

\section{Conclusions}

In this work, a method was developed to obtain fingerprint chromatograms by LC-DAD, which, together with PCA, proved to be adequate for $L$. alba quality control, since it allowed the discrimination of accessions from this species taking into account the extraction method and collection season of its leaves. This methodology allowed to differentiate the extracts prepared by infusion from those prepared by hydroalcoholic maceration. In addition, it was possible to propose that accessions LA01, LA39 and LA54 do not suffer a great effect of the seasonality considering their hydroalcoholic extracts. On the other hand, evaluating the infusions, it was possible to observe that seasonality has a significant effect on the chemical composition of accessions LA24, LA32, LA39 and LA54, but little influenced chemically LA01 and LA02, suggesting that the latter are more resistant to seasonal variation.

In addition, it was possible to assume that accessions LA39 and LA54 are genetically similar because they clustered, in the scores plot, considering the comparison of their extracts from the same preparation method and collection season simultaneously, which corroborates the results obtained from the chemical analysis of their essential oils. However, genetic studies are necessary to prove this hypothesis.

The results of the cytotoxic tests revealed that the extracts LA01IW, LA02IW, LA01HS, LA24HS, LA02HW, LA24HW, LA39HW and LA54HW showed better inhibition percentage against the HL-60 lineage, with values varying from 40.0 to $52.0 \%$, suggesting presence of potentially promising compounds in these preparations with respect to the antitumor activity against this lineage.

With respect to the anticholinesterase tests, the extracts studied had a low inhibitory effect against AChE, a few of which displayed percentages of enzymatic inhibition between 25.0 and $33.0 \%$ : LA01HS, LA02HS, LA24HS, LA01HW, LA02HW and LA54HW.

The combination of the results obtained by fingerprint using LC-DAD aided by PCA with those of the biological activities presented by the extracts revealed, in a rational and objective way, that the extraction method, seasonality and the individuality of each accession are variables that should be taken into account regarding the use of the species L. alba, because they may influence the chemical composition and therapeutic potentials of its extracts, as observed through cytotoxic and anticholinesterase assays. These results may contribute significantly to future studies regarding this species aiming at its therapeutic and/or economic potential.

\section{Acknowledgments}

This study was financed in part by the Coordenação de Aperfeiçoamento de Pessoal de Nível Superior, Brasil (CAPES), Finance Code 001. The authors thank the Brazilian funding agencies CNPq, FAPESB and FAPESP (PROEM 2014/50299-5, research grant 2013/01710-1 and 
PD grant 2014/11640-3) for their financial support and scholarships. A. F. B., E. R. P. F., D. P. B., C. L. C. and P. C. L. N. are grateful to CNPq for research fellowships.

\section{References}

1. Bores, A. M. G.; González, A. M. E.; Campos, A. R.; Toscano, S. C.; Flores, J. C. B.; Delgado, C. T. H.; Maya, F. S.; Meza, M. U.; Castro, I. P.; Acuña, C. L. C.; Acevedo, J. G. A.; J. Photochem. Photobiol., B 2017, 167, 72.

2. Timóteo, P.; Karioti, A.; Leitão, S. G.; Vincieri, F. F.; Bilia, A. R.; Food Chem. 2015, 175, 366.

3. Trevisan, M. T. S.; Marques, R. A.; Silva, M. G. V.; Scherer, D.; Haubner, R.; Ulrich, C. M.; Owen, R. W.; Rec. Nat. Prod. 2016, 10, 485 .

4. Santos, C. P.; Pinto, J. A. O.; Santos, C. A.; Cruz, E. M. O.; Blank, M. F. A.; Andrade, T. M.; Santos, D. A.; Alves, P. B.; Blank, A. F.; Ind. Crops Prod. 2016, 79, 205.

5. Pérez, S.; Meckes, M.; Pérez, C.; Susunaga, A.; Zavala, M. A.; J. Ethnopharmacol. 2005, 102, 1.

6. Trevisan, M. T. S.; Macedo, F. V. V.; Quim. Nova 2003, 26, 301.

7. Gomide, M. S.; Lemos, F. O.; Lopes, M. T. P.; Alves, T. M. A.; Viccini, L. F.; Coelho, C. M.; Rev. Bras. Farmacogn. 2013, 23, 895.

8. Funari, C. S.; Eugster, P. J.; Martel, S.; Carrupt, P. A.; Wolfender, J. L.; Silva, D. H. S.; J. Chromatogr. A 2012, 1259, 167.

9. Almeida, M. C. S.; Alves, L. A.; Souza, L. G. S.; Machado, L. L.; Matos, M. C.; Oliveira, M. C. F.; Lemos, T. L. G.; BrazFilho, R.; Quim. Nova 2010, 33, 1877.

10. Melo, J. O.; Bitencourt, T. A.; Fachin, A. L.; Cruz, E. M. O.; Jesus, H. C. R.; Alves, P. B.; Blank, M. F. A.; Franca, S. C.; Beleboni, R. O.; Fernandes, R. P. M.; Blank, A. F.; Scher, R.; Acta Trop. 2013, 128, 110.

11. Camêlo, L. C. A.; Blank, A. F.; Ehlert, P. A. D.; Carvalho, C. R. D.; Blank, M. F. A.; Mattos, J.; Sci. Plena 2011, 7, 050201-1.

12. Blank, A. F.; Camêlo, L. C. A.; Blank, M. F. A.; Pinheiro, J. B.; Andrade, T. M.; Niculau, E. S.; Alves, P. B.; Sci. World J. 2015, DOI 10.1155/2015/321924.

13. Peixoto, M. G.; Costa-Júnior, L. M.; Blank, A. F.; Lima, A. S.; Menezesa, T. S. A.; Santos, D. A.; Alves, P. B.; Cavalcanti, S C. H.; Bacci, L.; Blank, M. F. A.; Vet. Parasitol. 2015, 210, 118

14. Pereira, C.; Calhelha, R. C.; Barros, L.; Queiroz, M. J. R. P.; Ferreira, I. C. F. R.; Ind. Crops Prod. 2014, 52, 709.

15. Rates, S. M. K.; Toxicon 2001, 39, 603.

16. Veiga-Junior, V. F.; Pinto, A. C.; Quim. Nova 2005, 28, 519.

17. Prado, V. M. J.; Moraes, V. R. S.; Nogueira, P. C. L.; Cruz, E. M. O.; Blank, A. F.; Pereira-Filho, E. R.; Martins, L. R. R.; Quim. Nova 2012, 35, 1814.

18. Gobbo-Neto, L.; Lopes, N. P.; Quim. Nova 2007, 30, 374.

19. Martins, L. R. R.; Pereira-Filho, E. R.; Cass, Q. B.; Anal. Bioanal. Chem. 2011, 400, 469.
20. Bansal, A.; Chhabra, V.; Rawal, R. K.; Sharma, S.; J. Pharm. Anal. 2014, 4, 223.

21. Forim, M. R.; Perlatti, B.; Costa, E. S.; Magnani, R. F.; Souza, G. D.; Curr. Chromatogr. 2015, 2, 20.

22. Sun, J.; Chen, P.; J. Pharm. Biomed. Anal. 2012, 61, 142.

23. Yudthavorasi, T. S.; Wongravee, K.; Leepipatpiboon, N.; Food Chem. 2014, 158, 101.

24. Cui, L.; Zhang, Y.; Shao, W.; Gao, D.; Ind. Crops Prod. 2016, 85,29 .

25. Boufridi, A.; Quinn, R. J.; J. Braz. Chem. Soc. 2016, 27, 1334.

26. Infometrix; Pirouette, v. 4.0; Infometrix, USA, 2012.

27. Gomes, S. V. F.; Santos, A. D. C.; Moraes, V. R. S.; Martins, L. R. R.; Viana, M. D.; Blank, A. F.; Pereira-Filho, E. R.; Cass, Q. B.; Nogueira, P. C. L.; Alves, P. B.; Chromatographia 2010, $72,275$.

28. da Silva, T. B. C.; D’Sousa Costa, C. O.; Galvão, A. F. C.; Bomfim, L. M.; Rodrigues, A. C. B. C.; Mota, M. C. S.; Dantas, A. A.; dos Santos, T. R.; Soares, M. B. P.; Bezerra, D. P.; BMC Complementary Altern. Med. 2016, 16, 199.

29. Silva, J. I.; Moraes, M. C.; Vieira, L. C. C.; Corrêa, A. G.; Cass, Q. B.; Cardoso, C. L.; J. Pharm. Biomed. Anal. 2013, 73, 44.

30. Vilela, A. F. L.; Seidl, C.; Lima, J. M.; Cardoso, C. L.; Anal. Biochem. 2018, 549, 53.

31. Vanzolini, K. L.; Jiang, Z.; Zhang, X.; Vieira, L. C. C.; Corrêa, A. G.; Cardoso, C. L.; Cass, Q. B.; Moaddel, R.; Talanta 2013, 116, 647.

32. Deconinck, E.; Sacré, P. Y.; Courselle, P.; Beer, J. O.; J. Chromatogr. Sci. 2013, 51, 791.

33. Leme, G. M.; Coutinho, I. D.; Creste, S.; Hojo, O.; Carneiro, R. L.; Bolzani, V. S.; Cavalheiro, A. J.; Anal. Methods 2014, 6, 7781.

34. Snyder, L. R.; Kirkland, J. J.; Dolan, J. W.; Introduction to Modern Liquid Chromatography, $3^{\text {rd }}$ ed.; John Wiley \& Sons: Hoboken, 2010.

35. Collins, C. H.; Braga, G. L.; Bonato, P. S.; Fundamentos de Cromatografia; Editora da Unicamp: Campinas, 2006.

36. Lanças, F. M.; Sci. Chromatogr. 2009, 1, 51.

37. Souza, A. M.; Poppi, R. J.; Quim. Nova 2012, 35, 223.

38. Yang, W.; Hu, M.; Chen, S.; Wang, Q.; Zhu, S.; Dai, J.; Li, X.; Food Anal. Methods 2015, 8, 2360.

39. He, J.; Wu, X.; Kuang, Y.; Wang, T.; Bi, K.; Li, Q.; Asian J. Pharm. Sci. 2016, 11, 265.

40. Lu, Y.; Gao, B.; Chen, P.; Charles, D.; Yu, L. L.; Food Chem. 2014, 154, 262.

41. Bajoub, A.; Medina-Rodríguez, S.; Gómez-Romero, M.; Ajal, E. A.; Bagur-González, M. G.; Fernández-Gutiérrez, A.; CarrascoPancorbo, A.; Food Chem. 2017, 215, 245.

42. Papoutsi, Z.; Kassi, E.; Mitakou, S.; Aligiannis, N.; Tsiapara, A.; Chrousos, G. P.; Moutsatsou, P.; J. Steroid Biochem. Mol. Biol. 2006, 98, 63 . 
43. Murthy, K. N. C.; Kim, J.; Vikram, A.; Patil, B. S.; Food Chem. 2012, 132, 27.

44. Ibrahim, A.; Sobeh, M.; Ismail, A.; Alaa, A.; Sheashaa, H.; Sobh, M.; Badria, F.; Mol. Clin. Oncol. 2014, 2, 581.

45. Encalada, M. A.; Rehecho, S.; Ansorena, D.; Astiasarán, I.; Cavero, R. Y.; Calvo, M. I.; LWT--Food Sci. Technol. 2015, 63, 1016.

46. Araújo, C. R. M.; Santos, V. L. A.; Gonsalves, A. A.; Rev. Virtual Quim. 2016, 8, 1818.

47. Marques, T. H. C.; dos Santos, P. S.; de Freitas, R. M.; de Carvalho, R. B. F.; de Melo, C. H. S.; David, J. P.; David, J. M.; Lima, L. S.; Quim. Nova 2013, 36, 549.
48. Georgiev, M.; Alipieva, K.; Orhan, I.; Abrashev, R.; Denev, P.; Angelova, M.; Food Chem. 2011, 128, 100.

49. Trevisan, M. T. S.; Bezerra, M. Z. B.; Santiago, G. M. P.; Feitosa, C. M.; Verpoorte, R.; Braz-Filho, R.; Quim. Nova 2006, 29, 415.

50. Morais, S. M.; Lima, K. S. B.; Siqueira, S. M. C.; Cavalcanti, E. S. B.; Souza, M. S. T.; Menezes, J. E. S. A.; Trevisan, M. T. S.; Rev. Bras. Plant. Med. 2013, 15, 575.

Submitted: July 26, 2018

Published online: December 13, 2018 